\title{
Total Quality Management as a Tool for Decision Making
}

\author{
Md. Abdus Sabur
}

Associate Professor, Accounting, Govt. Titumir College, Dhaka, BANGLAESH

\begin{abstract}
TQM means keeping the organization running smoothly with continuous input from our owners/customers. The major components of TQM are quality information, rewards for results, cooperation, secured jobs, fairness, equitable compensation, employees ownership stake etc the guiding principles are customer satisfaction safety, elimination of errors and defects, continuous improvement, employee empowerment etc The major constraints are lack of top management support, commitment, over dependence on computerized quality control, no market research, management by fear etc.
\end{abstract}

Key words: Quality, ISO Standard, Global Market, Overseas Market, Manager, Corporate, JIT, Front Line Workers

JEL Classification Code: L15

\section{INTRODUCTION}

$\mathrm{T}$ otal quality management has evolved from the quality assurance methods that were first developed around the time of the First World War. The war effort led to large scale manufacturing efforts that often produced poor quality. To help correct this, quality inspectors were introduced on the production line to ensure that the level of failures due to quality was minimized. After the First World War, quality inspection became more commonplace in manufacturing environments and this led to the introduction of Statistical Quality Control (SQC), a theory developed by W. Edwards Deming. ${ }^{1}$ This quality method provided a statistical method of quality based on sampling. Where it was not possible to inspect every item, a sample was tested for quality. The theory of SQC was based on the notion that a variation in the production process leads to variation in the end product. If the variation in the process could be removed this would lead to a higher level of quality in the end product. After World War Two, the industrial manufacturers in Japan produced poor quality items. In a response to this, the Japanese union of Scientists and Engineers invited Deming to train Engineers in quality processes. By the 1950's quality control was an integral part of Japanese manufacturing and was adopted by all levels of workers within an organization. By the 1970's the notion of total quality was being discussed. This was seen as company-wide quality control that involves all employees from top management to the workers, in quality control. In the next decade more non-Japanese companies were introducing quality management procedures that based on the results seen in Japan. The new wave of quality control became known as Total Quality Management, which was used to describe the many qualities focused strategies and techniques that became the center of focus for the quality movement. ${ }^{2}$

The increasing need for improvement of quality the world over led to the development of quality systems to take care of all relevant aspects related to and influencing quality starting from product design and culmination in service to the user. The increase in product complexity and size of operation, responsibility for product quality is gradually shifted from operator to the quality control department. Quality is defined as the totality of features and characteristics of a product or service that bears on its ability to satisfy stated or implied needs. It is the degree to which a specific product conforms to a design specification.

The management is concerned with profitability, growth and resource generation. But only a few inspectors are responsible for checking product's quality. Customers in recent years have come to expect much higher quality than ever before. Parameters responsible for product quality and quality concepts need to be clearly understood by management. If one looks at concept of Quality and its progress over the years carefully, it is evident that Quality has always been an important element for the success of any organization. But the initial approach for Quality was concentrated on the final inspection and accordingly post production adjustment was made. Quality was not viewed as a responsibility of all employees. Quality function was separated from such areas as planning, design, production and sales.

\section{Statement of the Problem}

Many companies believe that costs of the introduction of TQM are far greater than the benefits it will produce. However research across a number of industries has costs involved in doing nothing, i.e. the direct and 
indirect costs of quality problems, are far greater than the costs of implementing TQM. An American quality expert, ${ }^{3}$ wrote that many companies chose to pay for the poor quality in what he referred to as the "Price of nonconformance". The costs are identified in the Prevention, Appraisal, and Failure (PAF) Model. Prevention costs are associated with the design, implementation and maintenance of the TQM system. They are planned and incurred before actual operation, and can include: Product Requirements, Quality Planning, Quality Assurance, and training. Appraisal costs are associated with the vendors and customers evaluation of purchased materials and services to ensure they are within specification. They can include: Verification, Quality Audits, and Vendor Evaluation.

Failure costs can be split into those resulting from internal and external failure. Internal failure costs occur when results fail to reach quality standards and are detected before they are shipped to the customer. These can include: Waste, Scrap, Rework, and Failure Analysis.

External failure costs occur when the products or services fail to reach quality standards, but are not detected until after the customer receives the item. These can include: Repairs, Warranty Claims, Complaints, and Returns.

\section{ObJectives OF THE STUdY}

The major objectives of the study are to high light the various uses of Total Quality Management (TQM) as a tool for managerial making. Another object is to find out the inherent constraints in its application followed by an attempt to recommend for the betterment of the situation.

\section{REVIEW OF RESEARCH Studies}

Milon Kumar Bhattacharjee \& Bidhan Mazumber ${ }^{4}$ authored and article on "Cost of Quality- A Step towards Measuring Total Management." This paper makes an effort to focus on the conceptual framework of Cost of Quality (COQ), an important technique for measuring Total Quality Management (TQM) as well as on it practices by the business enterprises of Bangladesh in order to produce qualitative product. The study reveals that a few of business enterprise in Bangladesh run their operation confirming to Total Quality Management in all respects and they are performing with a leading market share. Some of the enterprises feel the necessity of TQM but they have still not implemented it due to lack of clear knowledge and skilled personnel. All other enterprises have shown their ignorance about the TQM. It is important that cost should be controlled while TQM is implemented since these costs incur for improving the quality of product. So COQ must be taken into consideration for TQM. The study suggests that TQM should be implemented by the business enterprises in Bangladesh after calculating actual cost of quality so that the local products can easily compete with foreign products. Zahed Hossain Sikder and Dr. Mohammad Ayub Islam ${ }^{5}$ had a study on "ISO 9000-An Overview". The International
Organization for standardization (ISO) 9000 set of quality standards has been widely recognized and rapidly implemented world-wide since its inception without any change. These set of standards cover area such as product design and development, manufacturing, tension, inspection, employee training, understanding customer needs, verify and control the design process to meet customer's requirements, ${ }^{5}$ provide employees with correct documentation, assume responsibility for suppliers and internal quality, maintain tractability through the assembly process, and maintain appropriate records and documentation. It is also considered as a passport to enter into global market. There is number of variant of ISO series which highlight different aspect of quality standards. These standards cover ISO 90001, ISO 90002, ISO 90003, ISO 90004, ISO 10011, ISO 10012 and ISO 14000. Some procedural formalities and sequential steps are required to get ISO 9000 certification. Some of the multinational companies operating in Bangladesh have got this certification to retain their market share and to enter in the new overseas market. Very few private and public sector enterprises in Bangladesh have adopted this service standard of quality. This will reduce their share in export market. So there is an urgent need of these organizations to get ISO 9000 certification in order to retain their market share, expand their market and to compete with global players. This article gives an idea how to implement ISO 9000 quality standards in an organization as well as the formalities and procedures required for getting ISO 9000 certification.

Muhammad Ziaul Haq Manun and Sharmina Afrin ${ }^{6}$ in their study on "Total Quality Management (TQM) practices of the Bangladesh and Thai Companies: A Comparative Analysis" mentions that the comparative analysis of TQM practices between Bangladesh and Thai Companies clearly shows planning, implementation and operational difference, Bangladeshi companies portray TQM vision consciousness but in many cases they fall victim of treating TQM as a fad rather than an essential component. The management principles are narrowly viewed, communicated and understood in Bangladeshi companies even with well-documented procedures and instructions. All the Bangladeshi companies concerned are well equipped and successful to some extent in achieving customer satisfaction with regard to product and service quality excellence, but they lack close working relationships, interest groups and the promoting aspect of working environment. Bangladeshi firms make a visible effort in empowerment of quality control circles but apparently follow a comparatively rigid hierarchical structure, but nonetheless are able to assure quality. In terms of organization and distribution, all of the concerned companies are suitably equipped and positioned, but suppliers are not benchmarked with respect to specific criteria and special quality ratings in terms of product attributes and therefore information 
regarding supplier reliability is not available in any objective form. Bangladeshi firms have much to achieve in the areas of creativity and R\&D and therefore, investment in those areas in imperative.

Mohammad Moqbul Hossain Bhuiyan and Md. Kamal Uddin ${ }^{7}$ had an article on "What Does Total Quality Management Stand for? Literature Review and Implications for Bangladesh". They said that Quality control activities remain with us from thousands of years. Born out of management practice, the TQM (Total Quality Management) has had a profound and unparalleled impact on modern business history. However, as a body of practical knowledge, TQM has been largely theoretical. As a consequence, this important management philosophy has reminded amorphous and shrouded in considerable conceptual business and ambiguity in developing countries like Bangladesh. Recent theorizing, primarily emphasizing the application of organizational behavior theories of TQM has begun to provide greater clarity, but much work remains to be done. This paper attempts to contribute to this nascent theory-building literature by employing theory from market process economics, namely, Bangladeshi and evolutionary economics, which explains how processes of dynamic change, adaptation and learning are driven by entrepreneurial creativity. We have examined the perception of TQM of Bangladeshi management with the framework of modern econometrics techniques "Factor Analysis". Drawing on the resource approach and other theoretical perspectives, this paper has suggested TQM as a potential source of sustainable competitive advantage. Quality is to be managed, it must first be understood. Mangers must move aggressively to improve their understanding of quality practices and performance. The findings suggest that most features generally associated with TQM- such as training process improvement, and benchmarking do not generally produce advantage, but that certain tacit, behavioral, imperfectly imitable features - such as awareness, management commitment, open culture, employee empowerment, and executive commitment, leadership can produce advantage. The authors conclude that these tacit resources, and not TQM tools and techniques, drive TQM success, and those organizations that acquire them can outperform competitors with or without the accompanying TQM ideology.

\section{Methodology OF THE STUdY}

It is a theoretical approach based on desk study, review of related literature and existing stock of knowledge.

\section{FINDINGS OF THE STUDY}

TQM is an approach to improving the competitiveness, effectiveness and flexibility of an organization for the benefit of all stakeholders. It is a way of planning, organizing and understanding each activity, and of removing all the wasted effort and energy that is routinely spent in organizations. It ensures the leaders adopt a strategic overview of quality and focus on prevention not detection of problems. Whilst it must involve everyone, to be successful, it must start at the top with the leaders of the organization. All senior managers must demonstrate their seriousness and commitment to quality, and middle managers must, as well as demonstrating commitment, ensure they communicate the principles, strategies and benefits to the people for whom they have responsibility. Only then will the right attitudes spread throughout the organization. A fundamental requirement is a sound quality policy, supported by plans and facilities to implement it. Leaders must take responsibility for preparing, reviewing and monitoring the policy, plus take part in regular improvements of it and ensure it is understood at all levels of organization.

Effective leadership starts with the development of a mission statement, followed by a strategy, which is translated into action plans down through the organization. These combined with a TQM approach, should result in a quality organization, with satisfied customers and good business results. The 5 requirements for effective leadership in quantity management activity are:

- Developing and publishing corporate beliefs, values and objectives, often as a mission statement

- Personal involvement and acting as role models for a culture of total quality

- Developing clear and effective strategies and supporting plans for achieving the mission and objectives

- Reviewing and improving the management system

- Communicating, motivating and supporting people and encouraging effective employee participation

Total Quality Management is a system implemented to reduce defects in finished products with the goal of achieving zero products. These systems require timely data on defective products, rework costs, and the cost of honoring warranty contracts. This information is used to help to redesign the product in away that makes it less proves to defect. It may be used to reengineer the production process to reduce set up time and decrease the potential for error. TQM systems provide information on non-financial measures such as customer satisfaction, number of sense calls and time to generate reports. Attention to these measures which employees can control leads to increase profitability.

Just in time inventory systems demand for an increased emphasis on product quality. If products are produced only as they are needed. It is very costly for the company to have to stop production because of defects or machine breakdown. TQM and just in time production often aid in defective application of the lean business model. The main purpose of lean business model is to eliminate waste and strive for continuous improvement which requires that every manager and employee continuously look to 
improve operations. TQM calls for all managers and employees at all stages of operations to strive towards higher standards and a reduced number of defects.

In today's competitive and international market place, quality is synonymous with not just product quality but also cost, delivery and service. In a global market where product life cycle has become short where customer expectations have increased, the traditional product testing/certification approaches are not adequate. To compete in international markets, companies in developing countries need a sound quality management system. With liberalization and international competitiveness, there is need to improve the quality of goods manufactured by the industries. Standardization is one of the important tools for achieving quality up gradation and building a strong quality culture within the organization.

The basic elements of quality management are $:^{8}$

- An Appropriate infrastructure of "Quality System" encompassing the organizational structure, procedures, processes and resources.

- Systematic action necessary to ensure adequate confidence that a product (or service) will satisfy given requirements for quality.

The benefits of quality management system: ${ }^{9}$

- Satisfaction of customer's requirements through all stages guaranteeing all features.

- Customer confidence and creditability of the organization.

- Improvement in industry's competitiveness and reputation.

- Organizational development and total quality management.

- Continuous improvement.

Quality system consists of organization structure, procedures, processes, resources and responsibilities for implementing quality management.

\section{Characteristics of TQM}

(a) It focuses on serving customers.

(b) It is systematic problem solving using made up of front line workers.

(c) It uses bench marking studying organizations that are among the best in the world at performing a particular task.

(d) It is international in scope and is not confined to manufacturing activities only.

(e) It provides tools and techniques for continuous improvement based on facts and analysis.

(f) On proper implementation, it avoids counter productive organization in fighting.

(g) It improves productivity of an organization by using scientific knowledge in decision making and discouraging counter productive defensive behavior.

(h) It emphasizes a tem approach involving people who work directly in the process. ${ }^{10}$

\section{Dealing's Fourteen points ${ }^{11}$}

Presented below are Deming's fourteen points for total quality management.

$>$ Create constancy or purpose for improvement of product and service. (Plan to stay in business.)

$>$ Adopt the new philosophy. (Stop tolerating poor business.)

$>$ Cease dependence on inspection to achieve quality. (Improve the process.)

$>$ End the practice of awarding business on the basis of price tag alone. (Seek longer-term supplier relationships; reduce the number of suppliers.)

$>$ Improve constantly and forever every process in the system of planning, production and service.)

$>$ Institute modern training (for everyday.)

$>$ Institute modern methods of supervision,(The responsibility of foremen must be changed from sheer numbers to QUALITY.)

$>$ Drive out fear. (Encourage employees to speak up.)

$>$ Break down barriers between departments.

- Eliminate slogans, exhortations and targets for the work force.

$>$ Eliminate work standards that prescribe numerical quotas.

> Remove barriers to pride in workmanship(Poor supervisors, poor materials, inadequate equipment, lack of training, etc)

$>$ Institute a vigorous program of education and selfimprovement for everyone.

Place everybody in the company to work to accomplish the transformation and create a structure in top management that will push every day on the above points.

\section{Steps in implementing TQM ${ }^{12}$}

1. Obtain CEO Commitment

2. Educate Upper-Level Management

3. Create Steering Committee

4. Outline the Vision Statement, Mission Statement, \& Guiding Principles

5. Prepare a Flow Diagram of Company Processes

6. Focus on the Owner/Customer (External) \& Surveys

7. Consider the Employees as an Internet Owner/Customer

8. Provide a Quality Training Program

9. Establish Quality Improvement Teams

10. Implement Process Improvements

11. Use the Tools of TQM

12. Know the Benefits TQM

\section{Principles of TQM}

TQM can be defined as the management of initiatives and procedures that are aimed at achieving the delivery of quality products and services. A number of key principles can be identified in defining TQM including ${ }^{13}$

- Executive Management - Top management should act the main driver for TQM and create an environment that ensures it success. 
- Training - Employees should receive regular training on the methods and concepts of quality.

- Customer Focus - Improvements in quality should improve customer satisfaction.

- Decision Making - Quality decisions should be made based on measurements.

- Methodology and Tools - Use of appropriate methodology and tools ensures that nonconformances are identified, measured and responded to consistently.

- Continuous Improvement - Companies should continuously work towards improving manufacturing and quality procedures.

- Company Culture - The culture of the company should aim at developing employees ability to work together to improve quality.

\section{Challenges for using TQM}

The transformation to quality is not without its pitfalls. Many companies have started on the road to quality but failed to achieve success due to several factors:

- Lack of top management support.

- Lack of middle management support.

- Commitment in only one department.

- Short-term commitment-failure to stay on course.

- Hapazard approach- a little of this and that with no meaningful change in the system.

- Failure to acquire the services of a competent statistician or to provide statistical training for employees.

- Failure to solicit worker input.

- Over dependence on computerized quality control.

- Funding failure - lack of funds to make meaningful changes in the system (i.e. new machinery, training, improved raw materials.)

- No market research. Not knowing what the requirements are.

- No testing of incoming materials- garbage in- garbage out.

- Overselling hourly workers- expecting instant pudding

- Adversarial management (management by fear).

However with total commitment and constancy of purpose, these hazards can be overcome. ${ }^{14}$

\section{CONCLUSIONS}

TQM attempts to have maximum customer satisfaction through providing quality products and services but uncongenial business environment, high cost of production, increasing prices of products unfair competition in the market are the major constraints in using TQM. Once the business in profitable, they can develop quality products and services. Absence of breakeven point decline in demand for products, lack of trained manpower are other limiting factors for such use. We should try to have market research to satisfy our customers as well as managerial efficiency and effectiveness side by side. We should also develop strategic management techniques to stand in open market economy. Once the strategies are appropriate business can see well and further enhance the wide are of TQM devices towards the customer's goals achievement.

\section{BIBLIOGRAPHY}

[1] Garvin, David A. (1988) - Managing Quality - The Strategic and Competitive Edge, The Free Press; NY.

[2] Griffin, Ricky W. (2005) - Management (New York: Houghton Mifflin Company, $8^{\text {th }}$ Edition).

[3] Dean, J.W. and Evans. J.R (1994) - Total Quality Management, Organization and Strategy, New York: West Publishing Company.

[4] Bhattacharjee, Milon Kumar \& Mazumder, B.C. (2000) - Cost of Quality - A step towards Measuring Total Quality Management, The Chittagong University Journal of Commerce Vol.15.

[5] Sikder, Z,H. and Islam, Mohammad Ayub (2000) SO-9000-An Overview, The Chittagong University Journal of Commerce Vol.15.

[6] Mamun, M.Z and Afrin, S. (2001) - Total Quality Management (TQM) Practices of the Bangaldeshi and Thai Companies: A Comparative Analysis, Journal of Business Administration, Vol. 27, No. 1\&2, January \& April.

[7] Bhuiyan M.M.H. and Uddin, M.K.(2007) - What Does Total Quality Management stand for? Literature Review and Implications for Bangladesh, The Cost and Management, Vol. 35 No. 4 July-August.

[8] Goetsch, David L and Davis, Stanley B. (1997) "Introduction to Total Quallity", $2^{\text {nd }}$ ed. New Jersy, Prentice Hall.

[9] Bhuiyan M.M.H (2000) - Transier of Japanese Total Quality Control to the US Firms, Unpublished MBA Thesis, Otaru University of Commerce, Japan

[10] Goetsch, D.L. and S.B. Davis (1997) - Introduction to Total Quality (Upper Saddle River, NJ: Prentice Hall Inc.)

[11] Educational Foundation - TOTAL QUALITY MANAGEMENT : A CONTINUOUS IMPROVEMENT PROCESS 3 @ 1996 PHCC

[12] Educational Foundation - TOTAL QUALITY MANAGEMENT : A CONTINUOUS IMPROVEMENT PROCESS 10 @ 1996 PHCC

[13] Educational Foundation - TOTAL QUALITY MANAGEMENT : A CONTINUOUS IMPROVEMENT PROCESS 4 (C) 1996 PHCC

[14] Educational Foundation - TOTAL QUALITY MANAGEMENT : A CONTINUOUS IMPROVEMENT PROCESS 9 (c) 1996 PHCC 

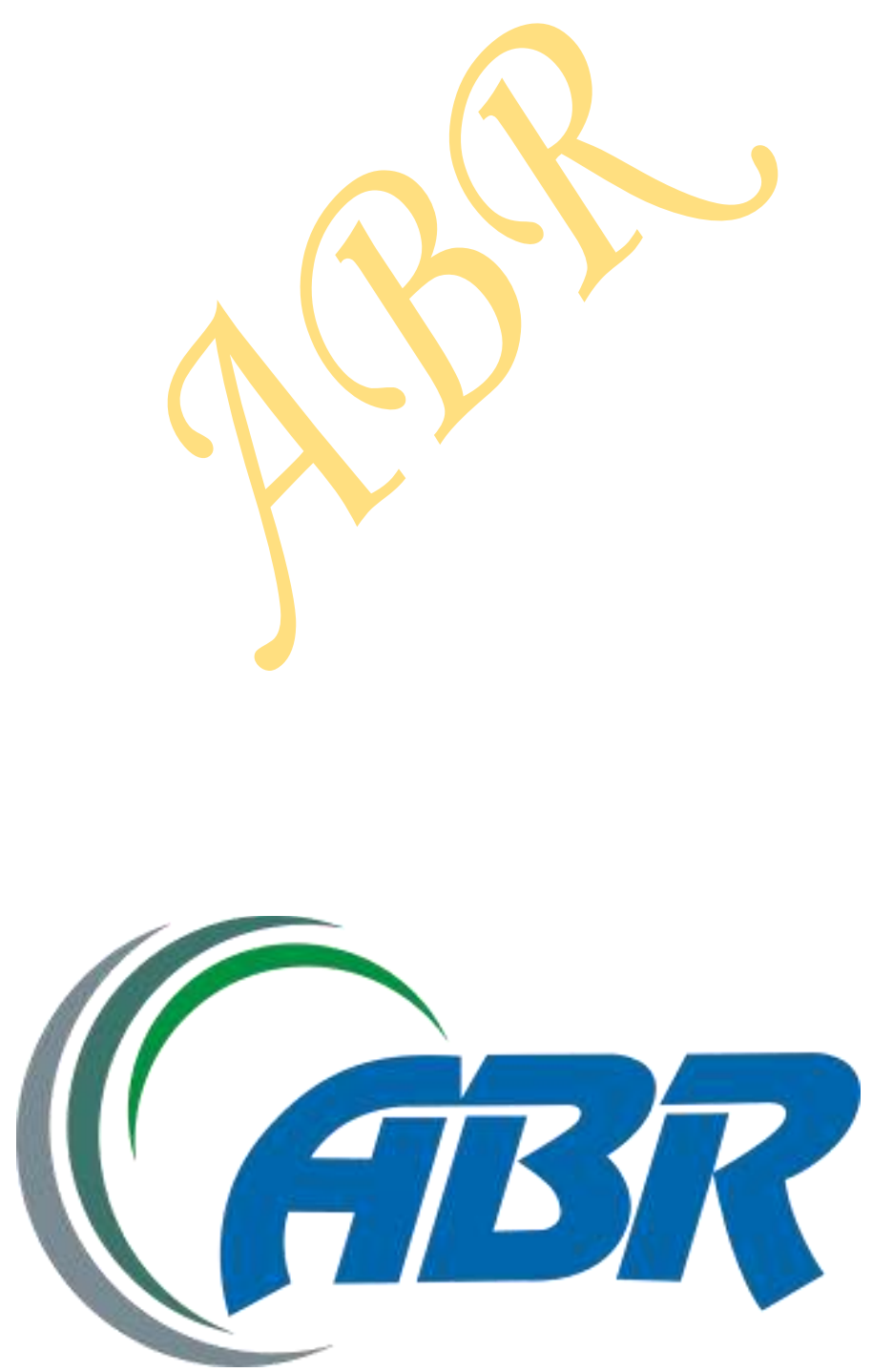